\title{
Improvement of the Working Memory and Naming by Transcranial Direct Current Stimulation
}

\author{
Seo Young Jeon, M.D., Soo Jeong Han, M.D., Ph.D.
}

Department of Rehabilitation Medicine, School of Medicine, Ewha Womans University, Seoul 158-710, Korea

\begin{abstract}
Objective To investigate the effects of transcranial direct current stimulation (tDCS) applied over the prefrontal cortex on the improvement of verbal, visuospatial working memory and naming in healthy adults.

Method Thirty two healthy adults ( 15 males and 17 females, mean age $37.3 \pm 13.0$ years) were enrolled in this study. The subjects were divided into four groups randomly. They underwent sham or anodal tDCS over the left or right prefrontal cortex, for 20 minutes at a direct current of $1 \mathrm{~mA}$. Before and immediately after tDCS, the subjects performed the Korean version of the mini-mental state exam (K-MMSE) and stroop test (color/word/interference) for the screening of cognitive function. For working memory and language evaluation, the digit span test (forward/ backward), the visuospatial attention test in computer assisted cognitive program (CogPack ${ }^{\circledR}$ ) and the KoreanBoston Naming Test (K-BNT) were assessed before tDCS, immediately after tDCS, and 2 weeks after tDCS.

Results The stroop test (word/interference), backward digit span test and K-BNT were improved in the left prefrontal tDCS group compared with that of the sham group $(\mathrm{p}<0.05)$. The stroop test (interference) and visuospatial attention test were in the right prefrontal tDCS group compared with that of the sham group $(\mathrm{p}<0.05)$. Their improvement lasted for 2 weeks after stimulation.

Conclusion tDCS can induce verbal working memory improvement and naming facilitation by stimulating the left prefrontal cortex. It can also improve the visuospatial working memory by stimulating the right prefrontal cortex. Further studies which are lesion and symptom specific tDCS treatment for rehabilitation of stroke can be carried out.
\end{abstract}

Key Words Transcranial direct current stimulation, Prefrontal cortex, Working memory, Naming, Language

Received May 18, 2012; Accepted August 1, 2012

Corresponding author: Soo Jeong Han

Department of Rehabilitation Medicine, School of Medicine, Ewha Womans University, 911-1, Mok-dong, Yangcheon-gu, Seoul 158-710, Korea

Tel: +82-2-2650-5035, Fax: +82-2-2650-5145, E-mail: ocrystal@ewha.ac.kr (c) This is an open-access article distributed under the terms of the Creative Commons Attribution Non-Commercial License (http:// creativecommons.org/licenses/by-nc/3.0) which permits unrestricted noncommercial use, distribution, and reproduction in any medium, provided the original work is properly cited.

Copyright (๑) 2012 by Korean Academy of Rehabilitation Medicine

\section{INTRODUCTION}

For a long time studies have incorporated the use of electrical currents with the purpose of medical treatment. The electrical stimulation over the brain began after 'Deep Brain Stimulation (DBS)' was developed. It is highly effective in the treatment of an increasing array of neurological and psychiatric disorders. Already considered as a standard and accepted treatment for Par- 
kinson's disease, ${ }^{1}$ depression, ${ }^{2}$ and minimally conscious states. $^{3}$

Afterwards, transcranial magnetic stimulation (TMS) and transcranial direct current stimulation (tDCS) were developed. These forms of stimulation are receiving much attention as an important field of research in neurorehabilitation. In the medical profession, these two non-invasive brain stimulations; TMS and tDCS have already been used actively for the study of experimental and therapeutic aims. Especially, tDCS has demonstrated beneficial effects on a wide range of diseases, for example, neurological conditions such as stroke and refractory epilepsy, ${ }^{4,5}$ psychiatric indications such as chronic depression and drug cravings, ${ }^{6,7}$ and pain conditions such as fibromyalgia. ${ }^{8}$

Besides the above studies of patients, many studies of normal healthy people who had no neurological abnormality were also carried out. ${ }^{9,10}$ Cohen et al.'s study ${ }^{9}$ was conducted based on the theory; the right parietal lobe has been suggested to be important for the development of intact numerical understanding during infancy and early childhood. ${ }^{11,12}$ Cohen et al. ${ }^{9}$ trained subjects for 6 days with artificial numerical symbols, during which they applied a concurrent weak current ( $1 \mathrm{~mA}$ ) to the subjects' left and right parietal lobes for 20 minutes. They found that during numerical learning, anodal stimulation to the right parietal lobe group caused better and more consistent performance in both the numerical stroop task and the number-to-space numerical task. The improvement was still present 6 months after the training.

Many of the studies focusing on cognitive function were conducted by prefrontal cortex stimulation. ${ }^{13}$ This is because the prefrontal cortex is widely known to be responsible for working memory, and besides, the prefrontal cortex incorporates a broader network of interconnected brain areas involved in working memory. These include the parietal and temporal association areas of the cerebral cortex, cingulate and limbic areas, and subcortical structures such as the mediodorsal thalamus and the basal ganglia. ${ }^{14,15}$ Especially, it is considered that visuospatial working memory is associated with the right cerebrum, and working memory associated with language is more related to the left cerebrum. ${ }^{16}$

Other language functions as well as verbal working memory are known to have a relationship with the prefrontal cortex. According to Perani et al., ${ }^{17}$ when right handed male participants performed lexical decision tasks, their PET results indicated that the dorsolateral frontal cortex of the left hemisphere was activated only when verbs are processed.

Generally, the speech center of the brain is located in the left hemisphere, ${ }^{18}$ and the left prefrontal cortex is deeply involved in verbal working memory. ${ }^{19,20}$ Because of that, in the studies published so far, which concern the relationship between tDCS and cognition or language, the researchers made a target of tDCS for the left prefrontal cortex or left language cortex in most cases. ${ }^{4,13,21}$

However, as the right prefrontal cortex would take on an important role for visuospatial working memory, ${ }^{19,20}$ tDCS on the right cerebrum can be worthwhile to study. Therefore, in this study, when performing tDCS in the left and right prefrontal cortex, respectively, we intend to identify changes in the working memory and naming function and the differences in such change compared with sham stimulation experiments. Through the above analysis, the ultimate aim of this study is that the effect that $\mathrm{tDCS}$ has on the working memory and naming function of normal healthy subjects, is identified and tDCS is clinically applied to patients who have cognitive and language dysfunction induced by stroke, on the basis of this effect.

\section{MATERIALS AND METHODS}

\section{Subjects}

Subjects consisted of 32 healthy adults (12 males, 20 females) aged $20-59$ years (mean $37.3 \pm 13.0$ years). The subjects were included if they received 30 points for the

Table 1. General Characteristics of the Subjects

\begin{tabular}{lcccc}
\hline & Right anodal & Left anodal & Right sham & Left sham \\
\hline Number (male/female) & $8(4 / 4)$ & $8(3 / 5)$ & $8(5 / 3)$ & $8(3 / 5)$ \\
Age (years) & $35.13 \pm 11.9$ & $39.50 \pm 15.1$ & $37.88 \pm 13.6$ & $36.50 \pm 13.4$ \\
Education (years) & $16.25 \pm 2.0$ & $16.00 \pm 1.9$ & $15.75 \pm 2.0$ & $16.25 \pm 1.3$ \\
\hline
\end{tabular}

Values are means \pm standard deviations 
Korean Mini-Mental State Examination (K-MMSE). All subjects were right-handed Korean language natives and their educational levels were equal to or higher than those of high school graduates. The subjects with any history of implanted metal objects, seizures or any other neurological disease were excluded (Table 1).

All 32 subjects were randomly divided into 4 groups, left anodal, left sham stimulation, right anodal and right sham stimulation. They were not informed as to which group they belonged to. The local ethics committee approved the study and all subjects gave written informed consent including information of side effects and risks that they might experience during the study.

This study was conducted with the approval of the relevant institutional review boards and the consent of the patients.

\section{Methods}

Transcranial direct current stimulation (tDCS): A direct current was transferred by a saline-soaked pair of surface sponge electrodes $\left(35 \mathrm{~cm}^{2}\right)$ and delivered by a specially developed, battery-driven, constant-current stimulator, Phoresor II Auto Model PM850 (IOMED, Salt Lake City, USA). The anodal electrode was placed on the left dorsolateral prefrontal cortex (DLPFC) in the left anodal and left sham stimulation groups. In the right anodal and right sham stimulation groups, anodal electrodes were applied to the right DLPFC. According to 10-20 electroencephalography systems, the left and right DLPFC areas were defined as F3 and F4, respectively. ${ }^{22}$ The cathodal electrode was placed over the contralateral supraorbital area in all four groups. The direct current was initially increased over several seconds ( $0-10$ seconds) until reaching $1 \mathrm{~mA}$, which was an intensity proven to be safe in Iyer's study. ${ }^{23}$ In the sham stimulation groups, the electrodes were placed in the same position as the DLPFC stimulations; however, the intensity of the current was gradually decreased after 10 seconds, then being turned off after 20 seconds as previously described. ${ }^{4}$ Both the real and sham stimulations were maintained for a total of 20 minutes.

Screening test: To monitor the side effects of tDCS and to compare cognition, the subjects took the K-MMSE and stroop tests before and immediately after tDCS. In addition, the stroop test was carried out not only immediately after tDCS, but also 2 weeks after tDCS. A stroop test consists of a 'Word' page with color names printed in black ink, a 'Color' page with Xs printed in colors, and a 'WordColor' page with words from the first page printed in colors from the second ('Interference' task). ${ }^{24}$ For all pages, four colors and/or color words are used (red, yellow, blue and green). The words and the colors are arranged in a $4 \times 5$ grid in evenly spaced rows and columns. ${ }^{25}$ The subject should name the color of ink in the 'Color' and 'Interference' pages, and read the word in the 'Word' page as quickly as possible. The reaction time was measured in seconds.

Outcome measurements: We evaluated the verbal, visuospatial working memory and naming function tests by a forward/backward digit span test, a visuospatial attention test of the computer assisted cognitive program and the K-BNT, respectively, as outcome measurements. Each test was performed 3 times; before tDCS, immediately after tDCS and 2 weeks after tDCS (Fig. 1). Prior to the baseline test, all tests were performed on the subjects by way of showing an example to minimize learning ef-

\begin{tabular}{|c|c|c|c|c|c|}
\hline \multirow{2}{*}{$\begin{array}{l}\text { K-MMSE } \\
\text { Stroop test (C/W/I) } \\
\text { Digit span (F/B) } \\
\text { Visuospatial test } \\
\text { K-BNT }\end{array}$} & \multirow{2}{*}{$\begin{array}{l}\begin{array}{l}\text { Lt anodal } \\
\text { stimulation }\end{array} \\
\begin{array}{l}\text { Rt anodal } \\
\text { stimulation }\end{array}\end{array}$} & & \multirow{2}{*}{$\begin{array}{l}\begin{array}{l}\text { Lt sham } \\
\text { stimulation }\end{array} \\
\begin{array}{l}\text { Rt sham } \\
\text { stimulation }\end{array}\end{array}$} & \multirow{2}{*}{$\begin{array}{l}\text { K-MMSE } \\
\text { Stroop test }(\mathrm{C} / \mathrm{W} / \mathrm{I}) \\
\text { Digit span }(\mathrm{F} / \mathrm{B}) \\
\text { Visuospatial test } \\
\text { K-BNT }\end{array}$} & \multirow{2}{*}{$\begin{array}{l}\text { Stroop test }(\mathrm{C} / \mathrm{W} / \mathrm{l}) \\
\text { Digit span }(\mathrm{F} / \mathrm{B}) \\
\text { Visuospatial test } \\
\text { K-BNT }\end{array}$} \\
\hline & & tDCs & & & \\
\hline $\bar{\varphi}$ & \multicolumn{3}{|c|}{$\overline{1}$} & $\bar{T}$ & $\bar{\varphi}$ \\
\hline Baseline test & \multicolumn{3}{|c|}{$\begin{array}{l}\text { tDCS by } 1 \mathrm{~mA} \text { for } 20 \text { minutes } \\
\text { (Sham stimulation: } 20 \text { seconds) }\end{array}$} & $\begin{array}{l}\text { Immediated after } \\
\text { tDCS }\end{array}$ & $\begin{array}{l}\text { Two weeks after } \\
\text { tDCS }\end{array}$ \\
\hline
\end{tabular}

Fig. 1. Study design for tDCS and sham stimulation groups. All participants were assessed before, immediately after and 2 weeks after stimulation. Lt: Left, Rt: Right, tDCS: Transcranial direct current stimulation, K-MMSE: Korean version of the mini-mental state exam, Stroop test (C/W/I): Stroop test (color/word/interference), Digit span (F/B): Digit span (forward/backward), Visuospatial test: Visuospatial attention test in the computer-assisted cognitive training program, K-BNT: Short parallel form of Korean-Boston Naming Test. 
fects through familiarization. One researcher tested the screening test, working memory and naming function, and the other researcher applied tDCS to subjects as per stimulation group. Therefore, the researcher in charge of the outcome measurement testing was unaware which stimulation was applied to the subject.

\section{Working memory}

Verbal working memory: The forward/backward digit span test was used to evaluate verbal working memory. The forward digit span test consists of orally presenting random number sequences (range 0-9) to the subject at a rate of approximately 1 per second. The subject must repeat the digits in the exact sequence in which they were presented. Following this, the examiner instructs the subject to repeat the orally presented digits backwards, as a backward digit span test. The examiner continues to add a digit every time the subject performs the task correctly. Scoring consists of the total number of digits the subject could correctly recall in the exact order they were presented or in reverse order. ${ }^{26}$ Maximum points were 9 in the forward digit span test and 8 in backward digit span test. ${ }^{26}$

Visuospatial working memory: The visuospatial function training, which is a subtask of the CogPack ${ }^{\circledR}$ (Marker Software, Ladenburg, Germany), a computer assisted cognitive program, was performed. When this program begins, a maze with a length, breadth and a diagonal line appears on a computer screen and then an image of a ball comes in from the left side and goes out through a particular route, which appears for ten seconds. The subject should watch this process carefully and remember the route that the ball went through. The participant follows the route of the ball exactly as shown by using a computer mouse after the ball completely disappears from the screen. The concordance rate between the route of both the ball and a computer mouse was recorded by a percentage (\%).

\section{Naming test}

We used parallel short forms of the Korean-Boston Naming Test for the naming function test. Parallel short forms of the Korean-Boston Naming Test (K-BNT) were developed to be able to conduct the test in a short period of time. A pre-existing original test with 60 -items was divided into 4 sets with 15 -items each to adjust the average level of the questions. The method of evaluation for test scores is as follows: four points are given for forward reaction without any hints, three points are given for for- ward reaction with meaningful hints, one point is given for forward reaction with a first syllable, half a point is given for forward reaction with a second syllable, and no points are given if there is no response. $60(15 \times 4)$ is the perfect score in each parallel test. ${ }^{27,28}$

Side effect of tDCS: All subjects should be asked to fill in a questionnaire about the side effect of tDCS. The questionnaire consisted of symptoms considered as side effects (headache; cervical pain; scalp pain; scalp numbness; scalp redness; drowsiness; feeling of difficult to concentration; sudden mood change etc.) and intensity of symptoms (no; mild; moderate; severe).

Statistical analysis: Analyses were performed with SPSS $^{\circledR}$ version 18.0 for Windows. We used the chi-square test and two-way analyses of variance (ANOVA) to compare baseline demographic characteristics, age and years of education among the four groups, respectively. All outcome measurements (stroop test; forward/backward digit span test; visuospatial attention test of computer assisted cognitive program and K-BNT) were performed before tDCS, immediately after and 2 weeks after tDCS were analyzed with the repeated measure ANOVA. In the repeated measure ANOVA, the inter-group differences were designated between the left anodal and left sham stimulation groups, and between the right anodal and right sham stimulation groups. The intra-group differences were designated as time points (before tDCS; immediately after tDCS and 2 weeks after tDCS). The post-hoc comparisons were carried out using the TukeyKramer test. The level of statistical significance for $\alpha$ was 0.05 and the $95 \%$ confidence intervals were provided.

\section{RESULTS}

\section{Baseline characteristics}

There were no significant differences among the 4 groups for age or years of education $(p>0.05)$ (Table 1$)$. Prior to the tDCS, there was no significant difference in all baseline tests; stroop test, forward/backward digit span test, visuospatial attention test of computer assisted cognitive program and K-BNT among the 4 groups (p>0.05) (Tables 2, 3).

\section{Screening test}

All of the 32 participants received a score of 30 in the K-MMSE, which was repeated to check for the change in 
Table 2. Test Performances of Left Anodal and Left Sham Stimulation Groups

\begin{tabular}{|c|c|c|c|c|}
\hline Task & Stimulation & $\begin{array}{l}\text { Before tDCS } \\
(95 \% \mathrm{CI})\end{array}$ & $\begin{array}{c}\text { Immediately after } \\
\text { tDCS (95\% CI) }\end{array}$ & $\begin{array}{c}2 \text { weeks after tDCS } \\
(95 \% \mathrm{CI})\end{array}$ \\
\hline \multirow[t]{2}{*}{ Stroop test: color (second) } & Lt anodal & $\begin{array}{c}8.68 \pm 1.9 \\
(7.821-8.792)\end{array}$ & $\begin{array}{c}8.74 \pm 3.5 \\
(7.525-8.994)\end{array}$ & $\begin{array}{c}8.55 \pm 2.6 \\
(7.413-8.734)\end{array}$ \\
\hline & Lt sham & $\begin{array}{c}8.45 \pm 0.3 \\
(8.345-8.628)\end{array}$ & $\begin{array}{c}7.81 \pm 2.7 \\
(7.421-8.411)\end{array}$ & $\begin{array}{c}7.95 \pm 3.2 \\
(7.556-8.592)\end{array}$ \\
\hline \multirow[t]{2}{*}{ Stroop test: word (second) } & $\mathrm{Lt}_{\text {anodal }}{ }^{\dagger}$ & $\begin{array}{c}11.90 \pm 2.3 \\
(10.457-12.383)\end{array}$ & $\begin{array}{c}9.72 \pm 1.7^{*} \\
(9.163-11.125)\end{array}$ & $\begin{array}{c}9.67 \pm 6.5^{*} \\
(8.935-12.659)\end{array}$ \\
\hline & Lt sham & $\begin{array}{c}10.82 \pm 1.8 \\
(9.248-11.613)\end{array}$ & $\begin{array}{c}10.73 \pm 2.6 \\
(8.932-12.071)\end{array}$ & $\begin{array}{c}10.55 \pm 2.4 \\
(8.689-12.428)\end{array}$ \\
\hline \multirow[t]{2}{*}{$\begin{array}{l}\text { Stroop test: interference } \\
\text { (second) }\end{array}$} & $\mathrm{Lt}_{\text {anodal }}{ }^{\dagger}$ & $\begin{array}{c}23.19 \pm 4.8 \\
(20.353-25.498)\end{array}$ & $\begin{array}{c}20.11 \pm 6.5^{*} \\
(18.265-25.773)\end{array}$ & $\begin{array}{c}20.05 \pm 7.8^{*} \\
(16.971-26.137)\end{array}$ \\
\hline & Lt sham & $\begin{array}{c}22.11 \pm 6.5 \\
(17.827-27.349)\end{array}$ & $\begin{array}{c}23.19 \pm 4.8 \\
(19.685-26.793)\end{array}$ & $\begin{array}{c}22.68 \pm 5.2 \\
(18.576-27.156)\end{array}$ \\
\hline \multirow[t]{2}{*}{ Forward digit span (number) } & Lt anodal & $\begin{array}{c}8.75 \pm 0.4 \\
(8.705-8.926)\end{array}$ & $\begin{array}{c}8.88 \pm 1.5 \\
(7.871-9.344)\end{array}$ & $\begin{array}{c}8.92 \pm 1.4 \\
(7.796-9.683)\end{array}$ \\
\hline & Lt sham & $\begin{array}{c}8.68 \pm 0.9 \\
(7.972-9.238)\end{array}$ & $\begin{array}{c}8.67 \pm 0.7 \\
(8.025-8.984)\end{array}$ & $\begin{array}{c}8.78 \pm 0.6 \\
(8.193-9.226)\end{array}$ \\
\hline \multirow[t]{2}{*}{ Backward digit span (number) } & Lt anodal $^{\dagger}$ & $\begin{array}{c}5.25 \pm 1.8 \\
(4.743-6.081)\end{array}$ & $\begin{array}{c}5.73 \pm 0.7^{*} \\
(5.162-6.285)\end{array}$ & $\begin{array}{c}5.81 \pm 0.9^{*} \\
(5.357-6.224)\end{array}$ \\
\hline & Lt sham & $\begin{array}{c}5.75 \pm 1.4 \\
(4.815-6.572)\end{array}$ & $\begin{array}{c}6.02 \pm 1.1 \\
(5.023-6.798)\end{array}$ & $\begin{array}{c}5.77 \pm 0.6 \\
(4.994-6.237)\end{array}$ \\
\hline \multirow[t]{2}{*}{ Visuospatial test (\%) } & Lt anodal & $\begin{array}{c}65.25 \pm 25.5 \\
(58.561-82.968)\end{array}$ & $\begin{array}{c}64.75 \pm 32.3 \\
(52.790-89.439)\end{array}$ & $\begin{array}{c}66.25 \pm 20.9 \\
(61.169-82.433)\end{array}$ \\
\hline & Lt sham & $\begin{array}{c}67.25 \pm 17.7 \\
(59.354-79.279)\end{array}$ & $\begin{array}{c}68.00 \pm 25.7 \\
(57.168-83.557)\end{array}$ & $\begin{array}{c}67.50 \pm 25.5 \\
(54.342-80.513)\end{array}$ \\
\hline \multirow[t]{2}{*}{ K-BNT (score) } & $\mathrm{Lt}_{\text {anodal }}{ }^{\dagger}$ & $\begin{array}{c}52.35 \pm 4.2 \\
(49.299-55.101)\end{array}$ & $\begin{array}{c}56.05 \pm 3.8^{*} \\
(52.684-58.712)\end{array}$ & $\begin{array}{c}55.68 \pm 8.2^{*} \\
(49.327-54.273)\end{array}$ \\
\hline & Lt sham & $\begin{array}{c}53.50 \pm 4.2 \\
(49.379-55.691)\end{array}$ & $\begin{array}{c}52.91 \pm 5.9 \\
(48.323-56.677)\end{array}$ & $\begin{array}{c}54.29 \pm 4.7 \\
(51.654-56.982)\end{array}$ \\
\hline
\end{tabular}

Values are mean \pm standard deviation

95\% CI: 95\% confidence interval, tDCS: Transcranial direct current stimulation, Visuospatial test: Visuospatial attention test in the computer assisted cognitive program, K-BNT: Short parallel form of Korean-Boston Naming Test ${ }^{*} \mathrm{p}<0.05$ : vs. the baseline within groups, ${ }^{\dagger} \mathrm{p}<0.05$ : significant time $\mathrm{x}$ intervention factor interaction

the participant's cognition immediately after tDCS. No change in the K-MMSE was observed.

In the 'word' test, the second subsection of the stroop test, there was significant time and group interaction by the repeated measure ANOVA in the left anodal stimulation ( $\mathrm{F}=3.67 ; \mathrm{p}=0.03$ ) (Table 2). Also, only the left anodal stimulation group showed statistically significant improvement compared with the baseline values as time passed $(\mathrm{p}<0.05)$. Moreover, in the 'interference' test, which was the third subsection of the stroop test, both the left and right anodal stimulation groups had significant time and group interaction in the repeated measure
ANOVA (left: $\mathrm{F}=14.67 ; \mathrm{p}=0.022$, right: $\mathrm{F}=18.87 ; \mathrm{p}=0.038$ (Tables 2, 3). Also, the left and right anodal stimulation groups showed statistically significant improvement in comparison to the baseline values, as time passed $(\mathrm{p}<0.05)$.

When comparing results between 'immediately after' and ' 2 weeks after' tDCS of the stroop test by independent T-test, there was no significant improvement in both the left and right anodal stimulation groups ( $p>0.05)$.

\section{Working memory}

Verbal working memory: Before and after tDCS, all 
Table 3. Test Performances of Right Anodal and Right Sham Stimulation Groups

\begin{tabular}{|c|c|c|c|c|}
\hline Task & Stimulation & $\begin{array}{c}\text { Before tDCS } \\
(95 \% \mathrm{CI})\end{array}$ & $\begin{array}{c}\text { Immediately after } \\
\text { tDCS (95\% CI) }\end{array}$ & $\begin{array}{c}2 \text { weeks after tDCS } \\
(95 \% \mathrm{CI})\end{array}$ \\
\hline \multirow[t]{4}{*}{ Stroop test: color (second) } & Rt anodal & $7.49 \pm 1.4$ & $7.40 \pm 2.4$ & $7.42 \pm 3.8$ \\
\hline & & $(6.296-7.618)$ & $(6.071-8.275)$ & $(5.867-9.232)$ \\
\hline & Rt sham & $8.67 \pm 1.9$ & $8.02 \pm 1.2$ & $7.99 \pm 3.1$ \\
\hline & & $(7.659-9.144)$ & $(6.729-8.688)$ & $(6.153-9.673)$ \\
\hline \multirow[t]{4}{*}{ Stroop test: word (second) } & Rt anodal & $9.28 \pm 1.6$ & $9.10 \pm 3.1$ & $9.20 \pm 2.7$ \\
\hline & & $(8.352-10.043)$ & $(7.794-11.258)$ & $(7.885-11.172)$ \\
\hline & Rt sham & $10.18 \pm 2.4$ & $10.20 \pm 4.2$ & $10.08 \pm 2.9$ \\
\hline & & $(9.265-11.528)$ & $(8.972-12.416)$ & $(9.371-11.739)$ \\
\hline \multirow{4}{*}{$\begin{array}{l}\text { Stroop test: interference } \\
\text { (second) }\end{array}$} & Rt anodal $^{\dagger}$ & $20.93 \pm 5.3$ & $18.42 \pm 3.3^{*}$ & $18.78 \pm 4.7^{*}$ \\
\hline & & $(17.642-22.453)$ & $(16.281-21.332)$ & $(16.836-21.578)$ \\
\hline & Rt sham & $19.43 \pm 7.0$ & $19.03 \pm 6.5$ & $19.20 \pm 7.2$ \\
\hline & & $(15.945-23.566)$ & $(16.852-24.371)$ & $(15.294-25.427)$ \\
\hline \multirow[t]{4}{*}{ Forward digit span (number) } & Rt anodal & $8.88 \pm 0.4$ & $8.75 \pm 0.5$ & $8.88 \pm 0.8$ \\
\hline & & $(8.628-9.045)$ & $(8.361-9.210)$ & $(7.956-9.351)$ \\
\hline & Rt sham & $8.75 \pm 0.5$ & $8.90 \pm 0.9$ & $8.88 \pm 0.5$ \\
\hline & & $(8.344-8.937)$ & $(8.274-9.528)$ & $(8.431-9.122)$ \\
\hline \multirow[t]{4}{*}{ Backward digit span (number) } & Rt anodal & $5.75 \pm 1.6$ & $5.85 \pm 0.7$ & $6.05 \pm 1.2$ \\
\hline & & $(5.274-7.282)$ & $(5.357-6.029)$ & $(5.338-7.561)$ \\
\hline & Rt sham & $5.45 \pm 1.3$ & $5.50 \pm 0.2$ & $5.85 \pm 1.9$ \\
\hline & & $(5.028-6.593)$ & $(5.287-6.247)$ & $(5.581-6.958)$ \\
\hline \multirow[t]{4}{*}{ Visuospatial training (\%) } & Rt anodal $^{\dagger}$ & $58.00 \pm 15.7$ & $62.25 \pm 30.5^{*}$ & $61.55 \pm 25.8^{*}$ \\
\hline & & $(52.287-70.174)$ & $(49.729-75.380)$ & $(50.268-74.592)$ \\
\hline & Rt sham & $60.25 \pm 35.4$ & $60.75 \pm 26.8$ & $58.25 \pm 37.5$ \\
\hline & & $(58.608-79.551)$ & $(56.398-76.823)$ & $(53.674-78.204)$ \\
\hline \multirow[t]{4}{*}{ K-BNT (score) } & Rt anodal & $57.25 \pm 2.1$ & $56.75 \pm 5.8$ & $56.00 \pm 6.4$ \\
\hline & & $(56.815-58.947)$ & $(53.573-60.032)$ & $(52.542-61.580)$ \\
\hline & Rt sham & $56.30 \pm 3.7$ & $56.66 \pm 2.6$ & $58.05 \pm 5.1$ \\
\hline & & $(54.721-58.935)$ & $(53.816-58.273)$ & $(52.452-50.557)$ \\
\hline
\end{tabular}

Values are mean \pm standard deviation

95\% CI: 95\% confidence interval, tDCS: Transcranial direct current stimulation, Visuospatial test: Visuospatial attention test in the computer assisted cognitive program, K-BNT: Short parallel form of Korean-Boston Naming Test ${ }^{*} \mathrm{p}<0.05$ : vs. the baseline within groups, ${ }^{\dagger} \mathrm{p}<0.05$ : significant time $\mathrm{x}$ intervention factor interaction

groups had no statistically significant differences in the forward digit span test. However, in the backward digit span test, only the left anodal stimulation group had significant improvement compared with baseline values by repeated measure ANOVA as time went by $(\mathrm{F}=6.38$; $\mathrm{p}=0.042$ ) (Table 2). On the other hand, in the left sham stimulation group, there was a score improvement compared with before the stimulation but it was not significantly different $(p>0.05)$ (Table 2$)$. In the right anodal and right sham stimulation comparison, there was no signifi- cant interaction between the time factor and groups by repeated measure ANOVA ( $p>0.05)$ (Table 3$)$.

When comparing between 'immediately after' and ' 2 weeks after' tDCS of the backward digit span test by independent T-test, there was no significant improvement in both the left and right anodal stimulation groups ( $\mathrm{p}>0.05)$.

Visuospatial working memory: As the tDCS schedule progressed, the results of the visuospatial attention test in the right anodal stimulation group demonstrated a 
statistically significant time factor and group interaction by repeated measure ANOVA ( $\mathrm{F}=7.31 ; \mathrm{p}=0.033$ ) (Table 3 ). However, the left anodal stimulation group and left sham stimulation group did not display any statistical significance by repeated measure ANOVA ( $p>0.05$ ) (Table 2).

When comparing between 'immediately after' and '2 weeks after' tDCS of the visuospatial attention test by independent T-test, there was no significant improvement in both the left and right anodal stimulation groups ( $>>0.05)$.

\section{Naming}

Both the right anodal stimulation group and right sham stimulation group did not have any interaction between the time factor and the groups by the repeated measure ANOVA in the K-BNT. However, the left anodal stimulation group showed significant improvement compared with the baseline values as time went by $(\mathrm{F}=4.16$; $\mathrm{p}=0.047$ ) (Table 2).

When comparing between 'immediately after' and '2 weeks after' tDCS of K-BNT by the independent T-test, there was no significant improvement in both the left and right anodal stimulation groups ( $\mathrm{p}>0.05)$.

\section{Side effect of tDCS}

Each person in both the left anodal stimulation group and the right stimulation group had no other side effects except for temporary headaches and temporary redness of the skin. The symptom of a minor headache in one of the participants went away after 20 minutes. In addition, a symptom in regards to the scalp turning red where the electrode was attached went away after a few hours. There were no participants who experienced drowsiness, carelessness or sudden change of mood.

\section{DISCUSSION}

In this study, when anodal stimulation was applied over the left prefrontal cortex, there were significant improvements in the 'Word' and 'Interference' subtests of the stoop test, backward digit span test and K-BNT compared to the left sham stimulation group. Also, when anodal stimulation was applied over the right prefrontal cortex, significant improvements were exhibited in the 'Interference' subtest of the stroop test, a visuospatial attention test of the computer assisted cognitive program com- pared with the right sham stimulation group.

Distinctively, in our results, the right anodal stimulation group's visuospatial attention test value revealed significant improvement compared to the right sham stimulation group. The computer assisted cognitive program used in this study was $\operatorname{CogPack}{ }^{\circledR}$, made in Germany, which is actively used for the treatment of cognitive dysfunction in schizophrenia. ${ }^{29}$ The visuospatial attention training, which was a subsection in this program, required that a subject remember the route of a ball and immediately follow the route by using a mouse. This activity required both the visual working memory and visuospatial perception. According to earlier studies, the lateral prefrontal cortex of the right hemisphere is concerned with visual working memory, ${ }^{30}$ and the right parietal cortex is most important to visuospatial perception. ${ }^{31}$ We performed right tDCS over the prefrontal cortex as an anodal stimulation target. Therefore, it can be understood in the same context with the above findings, which is that the visuospatial attention test showed significant improvement in the right prefrontal cortex anodal stimulation group. That is to say, additional stimulation on the right parietal lobe as well as direct stimulation on the right prefrontal cortex could be possible, due to the difficulty of stimulating a small area of the cortex, precisely. It is suggestive that these complex effects can improve performance in the visuospatial attention test taken by the right anodal prefrontal cortex stimulation group.

Previous studies have reported that when tDCS is applied over the left prefrontal cortex, working memory is improved. ${ }^{13,32}$ According to Boggio et al., ${ }^{32}$ when 18 patients with idiopathic Parkinson's disease performed a three-back working memory task during active anodal tDCS ( $2 \mathrm{~mA}$ ) of the left DLPFC for 20 minutes, the results demonstrated a significant improvement in working memory as indexed by task accuracy. The other conditions of stimulation: sham tDCS, anodal tDCS of LDLPFC with $1 \mathrm{~mA}$ or anodal tDCS of the motor cortex did not result in a significant change in task performance. ${ }^{32}$ Moreover, the study regarding normal healthy people was reported to have similar results with that of patients having Parkinson's disease. ${ }^{13}$ In Fregni et al.'s study, ${ }^{13} 15$ subjects (age 19-22 years) underwent a three-back working memory task based on letters. This task was performed during sham and anodal stimulation applied over the left dorsolateral prefrontal cortex for 10 minutes by $1 \mathrm{~mA}$. Fol- 
lowing that, only anodal stimulation of the left prefrontal cortex increased the accuracy of the task performance. ${ }^{13}$ As these reports coincided with this study's result, it is assumed that anodal tDCS induced cortical excitation, which was associated with polarity-driven alterations of the resting membrane potentials induced by the application of Na+-channel-blocking carbamazepine and the $\mathrm{N}$-methyl-D-aspartate-receptor antagonist dextromethorphan. ${ }^{10}$

Also, the left anodal stimulation group showed significant improvement in the K-BNT. Contrary to our study, when researchers intend to improve language function, interventions like tDCS over Broca's or Wernicke's area is common. There are several conventional studies on the relationship between tDCS and language function. ${ }^{33,34}$ You et al. ${ }^{33}$ demonstrated that right-handed subacute stroke patients with global aphasia due to ischemic infarct of the left middle cerebral artery were applied $2 \mathrm{~mA}$ tDCS, 5 times a week for 2 weeks, for 30 minutes per session. After the intervention, auditory verbal comprehension improved significantly more in patients treated with a cathodal tDCS applied to the right superior temporal gyrus, as compared to patients in the cathodal tDCS on the left superior temporal gyrus or sham stimulation groups..$^{33}$ And in Cattaneo's study of normal healthy subjects, ten healthy individuals performed a semantic and a phonemic fluency task following anodal tDCS applied over Broca's region. Participants were found to produce more words following real anodal tDCS in both phonemic and semantic fluency, compared with the sham stimulation group $(\mathrm{p}<0.05) .{ }^{34}$ However, recently, it is assumed that the prefrontal cortex's role in language function has emerged important, especially in regards to the naming function. ${ }^{35,36}$ In Shapiro et al.'s study, ${ }^{35}$ the researchers used event-related functional MRI to identify cortical regions that were active when English-speaking subjects produced nouns or verbs in the context of short phrases. Two regions, in the left prefrontal cortex and left superior parietal lobule, were selectively activated for verb trials compared with noun trials; one region in the left inferior temporal lobe was more active during noun production than verb production. Cotelli et al. ${ }^{36}$ reported that when they applied high-frequency repetitive transcranial magnetic stimulation to the left and right dorsolateral prefrontal cortex of fifteen patients with probable Alzheimer disease during object and action naming, there was significant improvement of accuracy in action naming $(\mathrm{p}<0.05)$. Besides the effect of tDCS on Broca's and Wernicke's areas, which is already known through previous studies, this study revealed that the tDCS over the left prefrontal cortex affected improvement of the naming function in language ability as well.

In this study, only transient headaches and redness of the scalp were reported as side effect of tDCS. tDCS over the frontal cortex is often applied for treatment of major depression and it can change moods. ${ }^{37}$ Therefore, the effect of tDCS on mood needs to be evaluated, however, no subject complained of sudden mood changes in our study. In Boggio et al.'s study, ${ }^{6} 40$ patients with major depression, medication-free, were randomized into three groups of treatment: anodal tDCS of the left dorsolateral prefrontal cortex; anodal tDCS of the occipital cortex and sham tDCS. tDCS was applied for 10 sessions during a 2 -week period. The researchers found significantly larger reductions in depression scores (Hamilton Depression Rating Scale) after dorsolateral prefrontal cortex tDCS compared to occipital and sham tDCS $(\mathrm{p}<0.05)$. The beneficial effects of tDCS in the dorsolateral prefrontal cortex group persisted for 1 month after the end of treatment. ${ }^{6}$ Unlike the major depression patient group, it is suggested that there were no systematic subjective or objective effects of bifrontal tDCS on mood or several measures of arousal and emotional cognition in healthy adults. ${ }^{38}$ However, when the side effects of tDCS are investigated, the researchers should keep these findings in mind.

At first, we included the stroop test in the outcome measurements because we wanted to evaluate general cognition before and after tDCS. However, improvements of performance in the stroop tests were shown after the left and right stimulation compared to the baseline test according to the results. The stroop test takes a familiarization process to exclude the learning effect like the other tests. Therefore, it is difficult to explain these results by only the learning effect, and it is required to investigate the meaning of this result. The stroop test is a representative tool for executive function tests in addition to the Wisconsin card sorting test, ${ }^{39}$ and the dominant brain area for executive function is widely known as the frontal cortex. ${ }^{40}$ It will be considered that anodal direct current has an effect on the whole frontal cortex over the prefrontal cortex such as the right parietal lobe according to these findings. In other words, it is expected that the 
stoop test is improved because tDCS has an effect on the frontal cortex.

In the last study, there was no difference between anodal stimulation and sham stimulation in both the left and right prefrontal cortex on the forward digit span test. Nine numbers were regarded as the perfect score of the forward digit span test in this study, and this level is considerably low compared to normal healthy subjects. Therefore, most subjects received a perfect score, and there was no statistical difference because of this. It is assumed that the forward digit span test is more appropriate for the evaluation of general cognition for before and after tDCS than the evaluation of the working memory. Nevertheless, it will be desirable if researchers are able to discriminate the significance of results by giving a higher level than 9 numbers.

This study has several limitations. First of all, the small sample size. Despite the considerable number of 32 participants, each group had only 8 subjects for comparison between the left $\cdot$ right anodal stimulation and left - right sham stimulation, respectively. Second, we only performed follow up tests 2 weeks after tDCS. If we performed more follow up tests with different periods, we could have detected persistent durations of tDCS effects and the changing patterns of each test more accurately

\section{CONCLUSION}

When tDCS is applied to the prefrontal cortex of normal healthy subjects' for 20 minutes, the working memory and naming function improved, and the beneficial effects persisted for at least 2 weeks after stimulation had ceased. Moreover, the left and right anodal stimulation on the prefrontal cortex showed significant improvement in distinct tasks, which were consistent with the left and right proper dominant function. This finding suggests that more specific tDCS treatment, based on brain lesions and symptoms for stroke or other neurologic disorders, would be possible.

\section{REFERENCES}

1. Benabid AL, Krack PP, Benazzouz A, Limousin P, Koudsie A, Pollak P. Deep brain stimulation of the subthalamic nucleus for Parkinson's disease: methodologic aspects and clinical criteria. Neurology 2000;
55: S40-44

2. Koller W, Pahwa R, Busenbark K, Hubble J, Wilkinson S, Lang A, Tuite P, Sime E, Lazano A, Hauser R, et al. High-frequency unilateral thalamic stimulation in the treatment of essential and parkinsonian tremor. Ann Neurol 1997; 42: 292-299

3. Stefurak T, Mikulis D, Mayberg H, Lang AE, Hevenor S, Pahapill P, Saint-Cyr J, Lozano A. Deep brain stimulation for Parkinson's disease dissociates mood and motor circuits: a functional MRI case study. Mov Disord 2003; 18: 1508-1516

4. Fregni F, Boggio PS, Mansur CG, Wagner T, Ferreira MJ, Lima MC, Rigonatti SP, Marcolin MA, Freedman SD, Nitsche MA, et al. Transcranial direct current stimulation of the unaffected hemisphere in stroke patients. Neuroreport 2005; 16: 1551-1555

5. Fregni F, Thome-Souza S, Nitsche MA, Freedman SD, Valente KD, Pascual-Leone A. A controlled clinical trial of cathodal DC polarization in patients with refractory epilepsy. Epilepsia 2006; 47: 335-342

6. Boggio PS, Rigonatti SP, Ribeiro RB, Myczkowski ML, Nitsche MA, Pascual-Leone A, Fregni F. A randomized, double-blind clinical trial on the efficacy of cortical direct current stimulation for the treatment of major depression. Int J Neuropsychopharmacol 2008; 11: 249-254

7. Fregni F, Liguori P, Fecteau S, Nitsche MA, PascualLeone A, Boggio PS. Cortical stimulation of the prefrontal cortex with transcranial direct current stimulation reduces cue-provoked smoking craving: a randomized, sham-controlled study. J Clin Psychiatry 2008; 69: 32-40

8. Fregni F, Gimenes R, Valle AC, Ferreira MJ, Rocha RR, Natalle L, Bravo R, Rigonatti SP, Freedman SD, Nitsche MA, et al. A randomized, sham-controlled, proof of principle study of transcranial direct current stimulation for the treatment of pain in fibromyalgia. Arthritis Rheum 2006; 54: 3988-3998

9. Cohen Kadosh R, Soskic S, Iuculano T, Kanai R, Walsh $\mathrm{V}$. Modulating neuronal activity produces specific and long-lasting changes in numerical competence. Curr Biol 2010; 20: 2016-2020

10. Liebetanz D, Nitsche MA, Tergau F, Paulus W. Pharmacological approach to the mechanisms of transcranial DC-stimulation-induced after-effects of human motor cortex excitability. Brain 2002; 125: 2238-2247 
11. Cantlon JF, Brannon EM, Carter EJ, Pelphrey KA. Functional imaging of numerical processing in adults and 4-y-old children. PLoS Biol 2006; 4: e125

12. Hyde DC, Boas DA, Blair C, Carey S. Near-infrared spectroscopy shows right parietal specialization for number in pre-verbal infants. NeuroImage 2010; 53: 647-652

13. Fregni F, Boggio PS, Nitsche M, Bermpohl F, Antal A, Feredoes E, Marcolin MA, Rigonatti SP, Silva MT, Paulus W, et al. Anodal transcranial direct current stimulation of prefrontal cortex enhances working memory. Exp Brain Res 2005; 166: 23-30

14. Constantinidis C, Procyk E. The primate working memory networks. Cogn Affect Behav Neurosci 2004; 4: 444-465

15. Gazzaley A, Rissman J, D’Esposito M. Functional connectivity during working memory maintenance. Cogn Affect Behav Neurosci 2004; 4: 580-599

16. Baddeley A. Working memory. Science 1992; 255: 556559

17. Perani D, Cappa SF, Schnur T, Tettamanti M, Collina S, Rosa MM, Fazio F. The neural correlates of verb and noun processing. A PET study. Brain 1999; 122: $2337-$ 2344

18. Damasio H, Grabowski TJ, Tranel D, Hichwa RD, Damasio AR. A neural basis for lexial retrieval. Nature 1996; 380: 499-505

19. Fletcher PC, Henson RN. Frontal lobes and human memory: insights from functional neuroimaging. Brain 2001; 124: 849-881

20. Walter H, Bretschneider V, Gron G, Zurowski B, Wunderlich AP, Tomczak R, Spitzer M. Evidence for quantitative domain dominance for verbal and spatial working memory in frontal and parietal cortex. Cortex 2003; 39: 897-911

21. Sparing R, Dafotakis M, Meister IG, Thirugnanasambandam N, Fink GR. Enhancing language performance with non-invasive brain stimulation-a transcranial direct current stimulation study in healthy humans. Neuropsychologia 2008; 46: 261-268

22. DaSilva AF, Volz MS, Bikson M, Fregni F. Electrode positioning and montage in transcranial direct current stimulation. J Vis Exp 2011; 51: 2744

23. Iyer MB, Mattu U, Grafman J, Lomarev M, Sato S, Wassermann EM. Safety and cognitive effect of frontal DC brain polarization in healthy individuals. Neurology
2005; 64: 872-875

24. Sbordone RJ, Saul RE, Purisch AD. Neuropsycology for psychologists, health care professionals, and attorneys, 3rd ed, Boca Raton: CRC Press, 2007, 153-189

25. Mitrushina MN, Boone KB, D'Elia LF. Handbook of normative data for neuropsychological assessment, New York: Oxford University Press; 1999, 74-100

26. Ahn HJ, Chin J, Park A, Lee BH, Suh MK, Seo SW, Na DL. Seoul Neuropsychological Screening Battery-dementia version (SNSB-D): a useful tool for assessing and monitoring cognitive impairments in dementia patients. J Korean Med Sci 2010; 25: 1071-1076

27. Kang Y, Kim H, Na DL. Parallel short forms for the Korean-Boston naming test (K-BNT). J Korean Neurol Assoc 2000; 18: 144-150

28. Lee JH, Yoo WK, Jung KI, Kim DH, Park DS, Im HJ. The therapeutic effect of inhibitory repetitive transcranial magnetic stimulation on right inferior frontal gyrus in subcortical aphasia. J Korean Acad Rehab Med 2007; 31: 70-77

29. Popov T, Jordanov T, Rockstroh B, Elbert T, Merzenich MM, Miller GA. Specific cognitive training normalizes auditory sensory gating in schizophrenia: a randomized trial. Biol Psychiatry 2011; 69: 465-471

30. Crottaz-Herbette S, Anagnoson RT, Menon V. Modality effects in verbal working memory: differential prefrontal and parietal responses to auditory and visual stimuli. Neuroimage 2004; 21: 340-351

31. Bestmann S, Thilo KV, Sauner D, Siebner HR, Rothwell JC. Parietal magnetic stimulation delays visuomotor mental rotation at increased processing demands. Neuroimage 2002; 17: 1512-1520

32. Boggio PS, Ferrucci R, Rigonatti SP, Covre P, Nitsche M, Pascual-Leone A, Fregni F. Effects of transcranial direct current stimulation on working memory in patients with Parkinson's disease. J Neurol Sci 2006; 249: 31-38

33. You DS, Kim DY, Chun MH, Jung SE, Park SJ. Cathodal transcranial direct current stimulation of the right Wernicke's area improves comprehension in subacute stroke patients. Brain Lang 2011; 119: 1-5

34. Cattaneo Z, Pisoni A, Papagno C. Transcranial direct current stimulation over Broca's region improves phonemic and semantic fluency in healthy individuals. Neuroscience 2011; 183: 64-70

35. Shapiro KA, Moo LR, Caramazza A. Cortical signa- 
tures of noun and verb production. Proc Natl Acad Sci U S A 2006; 103: 1644-1649

36. Cotelli M, Manenti R, Cappa SF, Geroldi C, Zanetti O, Rossini PM, Miniussi C. Effect of transcranial magnetic stimulation on action naming in patients with Alzheimer disease. Arch Neurol 2006; 63: 1602-1604

37. Nitsche MA, Boggio PS, Fregni F, Pascual-Leone A. Treatment of depression with transcranial direct current stimulation (tDCS): a review. Exp Neurol 2009; 219: 14-19

38. Koenigs M, Ukueberuwa D, Campion P, Wassermann E. Bilateral frontal transcranial direct current stimu- lation: failure to replicate classic findings in healthy subjects. Clin Neurophysiol 2009; 120: 80-84

39. Taylor J. Heritability of Wisconsin Card Sorting Test (WCST) and Stroop Color-Word Test performance in normal individuals: implications for the search for endophenotypes. Twin Res Hum Genet 2007; 10: 829834

40. Roca M, Parr A, Thompson R, Woolgar A, Torralva T, Antoun N, Manes F, Duncan J. Executive function and fluid intelligence after frontal lobe lesions. Brain 2010; 133: $234-247$ 